\title{
Appropriate Use of Ceftriaxone in Sub-Saharan Africa: A Systematic Review
}

\author{
Birhanu Meresa Bishaw \\ Gobezie T Tegegne (D) \\ Alemseged Beyene Berha \\ Department of Pharmacology and \\ Clinical Pharmacy, School of Pharmacy, \\ College of Health Science, Addis Ababa \\ University, Addis Ababa, Ethiopia
}

Correspondence: Gobezie T Tegegne

Department of Pharmacology and Clinical Pharmacy, School of Pharmacy, College of Health Science, Addis Ababa University, Addis Ababa, Ethiopia

Email gobezie.temesgen@aau.edu.et

\begin{abstract}
Introduction: Ceftriaxone is the most frequently used antibiotic for the treatment of various bacterial infections in hospitalized and ambulatory patients. Despite this, inappropriate ceftriaxone use is common.

Objective: The aim of this review is to assess the appropriate use of ceftriaxone in subSaharan African countries.

Methods: A systematic search was done on PubMed, EMBASE, Cochrane Libraries and Google Scholar for papers published addressing the prescribing pattern and use of ceftriaxone in sub-Saharan Africa. The findings were reported in medians and quartiles.

Results: A total of 15 articles met the inclusion criteria. Pneumonia and sepsis were the most frequently diagnosed infections in the included studies. The overall median prevalence of appropriate ceftriaxone use is 39.2\% (IQR: 29.9-60.9), showing that most of the included studies reported a higher prevalence of inappropriate ceftriaxone use. Although there are a higher number of patients with inappropriate use of ceftriaxone, a relatively higher number of patients got appropriate daily dose (79.8\%, IQR: 45.7-89.4) of ceftriaxone than appropriate duration of ceftriaxone (55\%, IQR: $52.2-80)$.

Conclusion: The review revealed that three in five patients with ceftriaxone got inappropriate ceftriaxone's dose, frequency or duration. A relatively higher number of patients got appropriate daily dose of ceftriaxone. On the other hand, approximately more than half of the patients got inappropriate duration, too short or too long, of ceftriaxone. Hence, prescribers are recommended to adhere to their country-specific treatment guideline. Moreover, it is highly recommended to either commence or strengthen antimicrobial stewardship program effectively in their healthcare settings.
\end{abstract}

Keywords: ceftriaxone, ceftriaxone use evaluation, prescribing pattern, sub-Saharan Africa

\section{Introduction}

The quality of health and medical care is determined by the rational prescribing and appropriate use of drugs. ${ }^{1}$ The introduction of antibiotics during mid-20th century significantly reduces patients' morbidity and mortality, and associated healthcare costs. Antibiotics are highly prescribed medications in low- and middle-income countries. $^{2}$ However, they are also inappropriately used medications. ${ }^{3-5}$ Appropriate antibiotic use is associated with a higher proportion of unsuccessful patient outcomes (including death, re-operation, re-hospitalization or additional parental antibiotic therapies), increased length of hospital stay and treatment, ${ }^{6}$ increased 30-day and in-hospital mortality, ${ }^{7}$ treatment failure, and increased cost of treatment. ${ }^{8}$ The problem also contributes to high rates of antibiotic resistance, ${ }^{9-11}$ one of the top ten global public health threats facing humanity. ${ }^{12}$ 
Due to its cost-effective and safety profile, ceftriaxone is one of the most widely used antibiotics in sub-Saharan Africa $(\mathrm{SSA})^{13,14}$ to treat different types of infections including lung infections, central nervous system infections, bone infections, abdominal infections, skin and soft tissue infections, and urinary tract infections. However, a higher rate of inappropriate use was reported in different studies. ${ }^{15,16}$ In addition, bacterial resistance is increasingly common among ceftriaxone users, raising concern that it may be no longer effective for infection treatment in East Africa. ${ }^{17,18}$ Inappropriate use is the main driving force for the development of antimicrobial resistance. Because bacteria will eventually develop means to avoid being killed by antibiotics, judicious use of antibiotics by all stakeholders is imperative. ${ }^{19}$ However, there are no organized data showing the extent of appropriate ceftriaxone use in SSA countries. The review is, therefore, aimed at summarizing the proper use of ceftriaxone in this region.

\section{Methods}

This systematic review was performed based on the Preferred Reporting Items for Systematic Review and Meta-Analysis Protocols (PRISMA-P) 2015 guidance. $^{20}$

\section{Data Source and Eligibility Criteria}

A systematic search was conducted on PubMed, Google Scholar, EMBASE and Cochrane Libraries. Boolean operators ("OR," "AND") and truncation were used to identify relevant articles that meet the research question. The search was conducted with the aid of carefully selected keywords and indexing terms. In addition, a reference list of included articles was evaluated for inclusion. A systematic search of the literature was conducted among studies published from 1st January 2010 to 30th February 2020.

All studies that focused on ceftriaxone prescribing pattern and rational use in SSA countries were included. In addition, studies must use appropriate antibiotic use guideline (eg IDSA) to evaluate indication, dose, dosage, frequency and duration of ceftriaxone.

\section{Inclusion and Exclusion Criteria}

All observational studies published in English language that address ceftriaxone use pattern and rational use in SSA countries were included. However, conference abstracts, editorial reports, or letters to the editors, case reports, case series and studies with limited information were excluded.

\section{Search Strategy}

The following search terms were used: "ceftriaxone use evaluation*", "ceftriaxone prescribing pattern", "cephalosporin use", "antibiotic use pattern", and "sub-Saharan". All search results from each database were saved, and exported into covidence. Duplicate studies were removed. The initial title and abstract screening were done by ABB and BMB. Three categories (yes, no, maybe) were used during the selection process. The full text of studies judged as 'yes' or "maybe" during initial screening was assessed based on the eligibility criteria by ABB and BMB. In both initial and full-text assessments, the third author (GTT) resolved any discrepancies arising between the two authors (ABB and BMB) (Figure 1).

\section{Data Extraction}

$\mathrm{ABB}$ and $\mathrm{BMB}$ independently extract relevant data using a standardized data abstraction format. These include study characteristics (study setting, and design, and sample size) and the result of studies (ceftriaxone use pattern, inappropriate of prescribing pattern and use of ceftriaxone). All disagreements were resolved by the third author (GTT).

\section{Study Quality Assessment}

The methodological quality and risk of bias of the included studies were independently assessed by two authors (ABB and BMB) using the Newcastle-Ottawa scale. $^{21}$ The scale rates study quality out of 10 points (stars). For ease of evaluation, the tool included important indicators categorized into three major domains. The first section assesses the methodological quality of a study, which has a maximum of 5 stars. The second section considers the comparability of the study and takes 2 stars, and the remaining section assesses the outcomes of studies related to the statistical analysis. The mean score of these two authors was taken for the final decision, and studies with a score of five and above points/stars were considered as good quality (Table 1).

\section{Data Analysis}

The extracted data were entered and analyzed using Statistical Package for the Social Sciences (SPSS) version 25.0 software. The prevalence of appropriate ceftriaxone indication, dose, frequency and duration of was summarized in medians and interquartile ranges. 


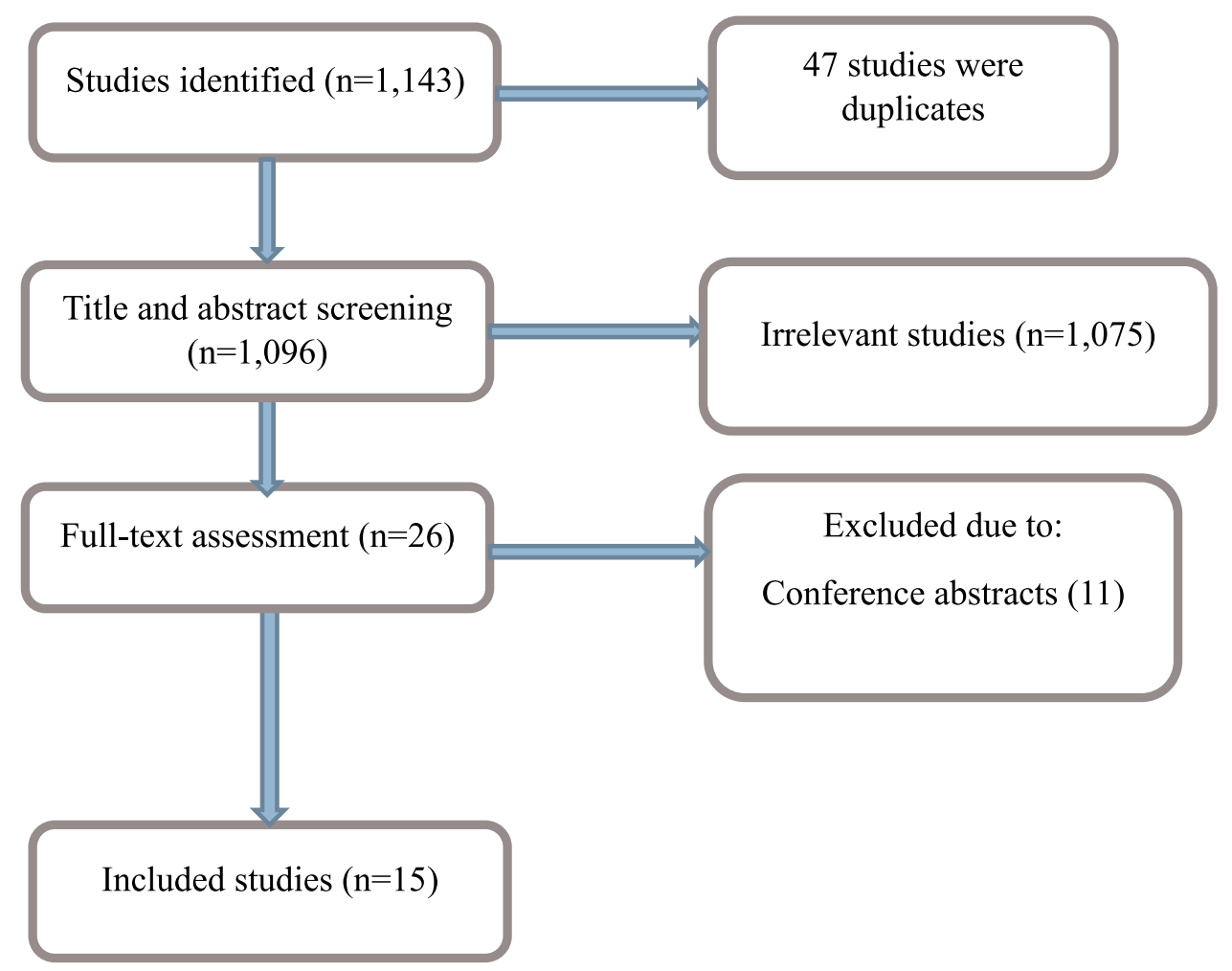

Figure I Article screening process.

\section{Definition of Terms}

Sub-Saharan Africa: Is geographically and ethnoculturally the area of the continents of Africa that lies south of the Sahara.

Appropriate use of ceftriaxone: It refers to the use of ceftriaxone to the right indication at the right dose, frequency, route and duration, and its value was taken directly from the included studies.

\section{Results}

\section{General Characteristics of the Included Studies}

Of the 1143 studies, 15 fulfilled the inclusion criteria. Out of 15 studies, eight in Ethiopia, three in Tanzania, one in Uganda, one in Ghana, one in Sudan, and one in Eritrea. Only two studies were conducted at both public and private hospitals, while the remaining were done at public hospitals. In addition, nine studies used retrospective cross-sectional study design, and the rest of studies employed prospective cross-sectional study design. A total of 4706 patients were involved in the review, and 90-601 patients were also targeted in the individual study. The highest appropriate ceftriaxone use (93\%) was reported in Ghana ${ }^{22}$ got appropriate ceftriaxone, whereas the lowest (6.7\%) was seen in Sudan ${ }^{23}$ (Table 2).

\section{Ceftriaxone Use Pattern and Appropriateness}

Ceftriaxone is used for the treatment of various infections. The frequent diagnosed infections are; pneumonia (a median of 24.8\%, (IQR: $16.2-31.1$ )), sepsis (a median of 9.2\%, (IQR: 3.7-16.1)), for surgical prophylaxis (a median of 7.7\%, (IQR: 0-20.7)), meningitis (a median of 7.5\%, (IQR: 3-20.9)), and urinary tract infection (a median 7.2\%, (IQR: 4.5 13.1)). Ceftriaxone is appropriately used for a median of 39.2\% (IQR: 29.9-60.9) of surgical patients. The highest median percentage of patients (51.2\%, IQR; 33.1-73.4) got 2-7 days of ceftriaxone, while the lowest median percentage of patients $(2.2 \%$, IQR: 0.6-3.85) got ceftriaxone for more than two weeks. In addition, a higher median of $73.3 \%$ (IQR: 51.5-77.8) ceftriaxone users used $2 \mathrm{gm}$ daily dose, while the lowest percentage of ceftriaxone users (0.8\%, IQR: $0.3-1.5)$ used $3 \mathrm{gm}$ daily. Afriyie et $\mathrm{al}^{22}$ reported that the daily dose of ceftriaxone was administered appropriately to all patients; on the contrary, lowest percentage of patients (18.0\%) got appropriate daily dose in Manirakiza et al. study. ${ }^{28}$ The 
Table I Study Quality Assessment Using Newcastle-Ottawa Quality Assessment Scale

\begin{tabular}{|c|c|c|c|c|c|}
\hline S.n & Author Yr (Ref) & $\begin{array}{l}\text { Methodological } \\
\text { Quality (4pts) }\end{array}$ & Comparability (2) & $\begin{array}{l}\text { Outcome Measurement and } \\
\text { Analysis (2) }\end{array}$ & Total (8) \\
\hline 1 & Abebe FA et al. $2012^{24}$ & 3 & I & 1.5 & 5.5 \\
\hline 2 & Afriyie DK et al. $2017^{22}$ & 3 & I & 1.5 & 5.5 \\
\hline 3 & Ayele AA et al. $2018^{16}$ & 3.5 & I & 1.5 & 6 \\
\hline 4 & Ayinalem GA et al. $2013^{25}$ & 3 & I & 1.5 & 5.5 \\
\hline 5 & Bantie et al. $2014^{26}$ & 3 & I & 1.5 & 5.5 \\
\hline 6 & Berhe $\mathrm{YH}$ et al. $2019^{15}$ & 3 & 1.5 & 1.5 & 6 \\
\hline 7 & Eulambius $M$ et al. $2019^{27}$ & 3 & 0.5 & 2 & 5.5 \\
\hline 8 & Manirakiza L et al. $2019^{28}$ & 3.5 & 0.5 & 2 & 6 \\
\hline 9 & Sasi $P$ et al. $2019^{29}$ & 3.5 & 2 & 2 & 7.5 \\
\hline 10 & Hussien LA. $2019^{23}$ & 3.5 & 1.5 & 2 & 7 \\
\hline II & Negese $S$ et al. $2017^{30}$ & 3.5 & 1.5 & 2 & 7 \\
\hline 12 & Shimels T et al. $2015^{31}$ & 3.5 & 1 & 1.5 & 6 \\
\hline 13 & Sonda TB et al. $2019^{14}$ & 3.5 & 1 & 1.5 & 6 \\
\hline 14 & Geresu G et al. $2018^{32}$ & 2.5 & I & 1.5 & 5 \\
\hline 15 & Muhammed OS et al. $2020^{33}$ & 3 & I & 1.5 & 5.5 \\
\hline
\end{tabular}

median prevalence of patients with appropriate daily dose of ceftriaxone was $79.8 \%$ (IQR: 40.9-91.0\%). Shimels et $\mathrm{al}^{31}$ reported the highest percentage of patients with appropriate duration of ceftriaxone $(91.5 \%)$, while the lowest prevalence (18.0\%) was reported by Negese et al. study. ${ }^{30}$ The overall median percentage of $(55 \%$, IQR: 52.2-80) patients got an appropriate duration of ceftriaxone (Table 3).

\section{Discussion}

Dramatic increase in antibiotic utilization in the healthcare system contributes to inappropriate antibiotic use, and continues to drive antibiotic resistant microbes. This will return disease management back to the pre-antibiotic era whereby people were dying due to minor infections. Hence, judicious use of these precious substances is very essential. However, empiric prescription of broadspectrum antibiotic for various diseases for very short or prolonged duration becomes a common practice in developing countries. This review was designed to systematically assess the appropriateness of ceftriaxone use in SSA countries. Our review showed that ceftriaxone was frequently used for pneumonia (a median of $24.8 \%$ ), sepsis (a median of 9.2\%), for surgical prophylaxis (a median of $7.7 \%$ ), meningitis (a median of 7.5\%), and urinary tract infections (a median 7.2\%). Ceftriaxone is a drug of choice for various bacterial infections, ranging from mild to life threatening conditions, in both hospitalized and ambulatory patients due to its higher antibacterial potency and low potential toxicity. ${ }^{34}$ In addition, it is easily available, cost-effective, broad-spectrum antibiotic, and usually prescribed empirically without supported by microbiological testing.

Despite inconsistencies among studies regarding study design and study population, the review found that a median of 39.2\% (IQR: 29.9-60.9) of patients got appropriate ceftriaxone use. Ceftriaxone was inappropriately prescribed for more than half of the patients. This may be due to inappropriate use of ceftriaxone during perioperative period as prophylaxis, and wrong indication, dose, frequency and duration. In addition, unavailability of alternative antibiotics and inconsistency of drug supply may contribute to the inappropriate use of ceftriaxone. Although there is no review conducted particularly in ceftriaxone use, a relatively higher percentage of appropriate antibiotic use $(51.8 \%, 95 \%$ CI: $32.2-66.2)$ was 


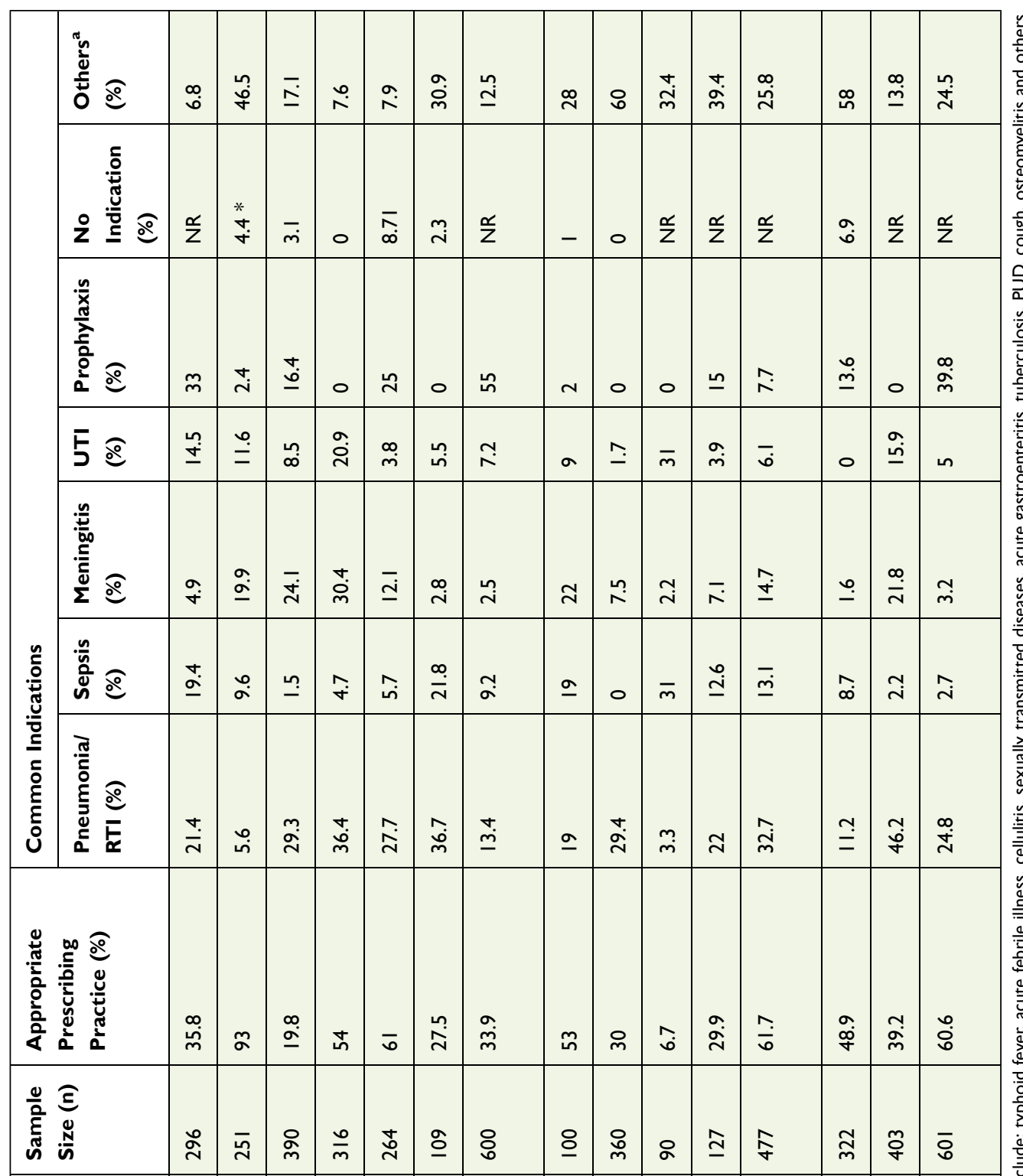

\begin{tabular}{|c|c|c|c|c|c|c|c|c|c|c|c|c|c|c|c|}
\hline 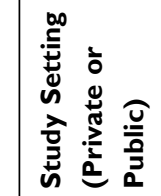 & $\frac{\frac{u}{0}}{\frac{0}{a}}$ & $\frac{\frac{u}{0}}{\bar{a}}$ & $\frac{\frac{u}{0}}{0}$ & $\begin{array}{l}\frac{\underline{u}}{\bar{a}} \\
\underline{a}\end{array}$ & $\frac{\frac{u}{0}}{\frac{0}{0}}$ & 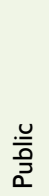 & 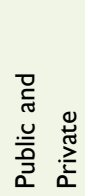 & $\frac{\frac{u}{\bar{a}}}{\frac{a}{2}}$ & 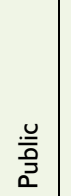 & $\frac{\frac{\underline{u}}{\bar{a}}}{\underline{0}}$ & $\frac{\frac{u}{\bar{a}}}{\frac{0}{0}}$ & 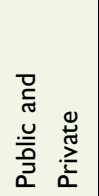 & $\frac{\frac{u}{\bar{a}}}{\frac{a}{2}}$ & $\frac{\underline{0}}{\frac{0}{0}}$ & 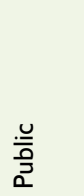 \\
\hline 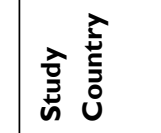 & 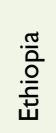 & $\begin{array}{l}\text { 胥 } \\
\text { 定 }\end{array}$ & 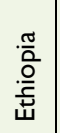 & 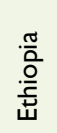 & 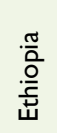 & 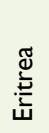 & 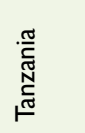 & 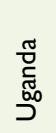 & 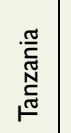 & $\begin{array}{l}\frac{\pi}{\pi} \\
\stackrel{5}{5}\end{array}$ & 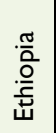 & 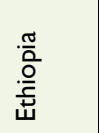 & 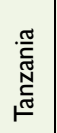 & 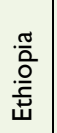 & 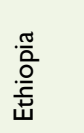 \\
\hline 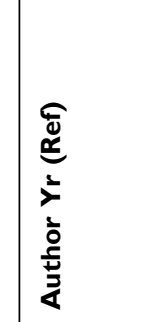 & 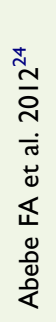 & 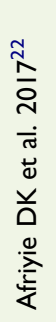 & 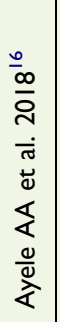 & 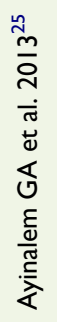 & 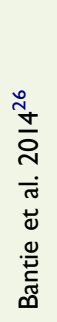 & 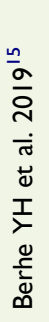 & 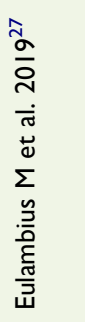 & 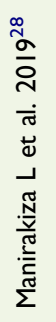 & 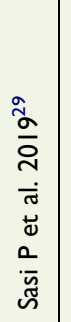 & 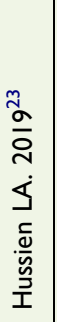 & 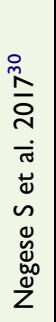 & 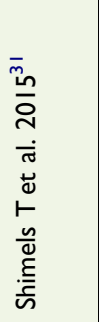 & 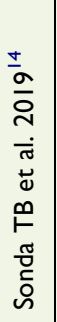 & 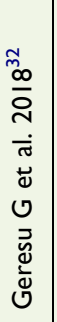 & 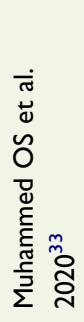 \\
\hline ตุ & - & N & $m$ & $\sigma$ & n & 0 & 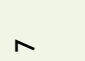 & $\infty$ & $\alpha$ & 으 & $=$ & $\simeq$ & $\underline{m}$ & \pm & $\underline{\text { 으 }}$ \\
\hline
\end{tabular}


Table 3 Pattern of Ceftriaxone Use in the Included Studies

\begin{tabular}{|c|c|c|c|c|c|c|c|c|c|c|c|c|}
\hline \multirow[t]{2}{*}{ S.n } & \multirow[t]{2}{*}{ Author Yr (Ref) } & \multicolumn{4}{|c|}{$\begin{array}{l}\% \text { of Patients Who Used the } \\
\text { Specified Dose of } \\
\text { Ceftriaxone Daily }\end{array}$} & \multirow{2}{*}{$\begin{array}{l}\text { \% of Patients } \\
\text { with } \\
\text { Appropriate } \\
\text { Daily } \\
\text { Ceftriaxone } \\
\text { Dose (\%) }\end{array}$} & \multicolumn{5}{|c|}{$\begin{array}{c}\% \text { of Patients Who Used the Specified } \\
\text { Duration of Ceftriaxone }\end{array}$} & \multirow{2}{*}{$\begin{array}{l}\% \text { of Patients } \\
\text { with } \\
\text { Appropriate } \\
\text { Ceftriaxone } \\
\text { Duration (\%) }\end{array}$} \\
\hline & & $<2 \mathrm{gm}$ & $2 \mathrm{gm}$ & $3 g m$ & $4 \mathrm{gm}$ & & Stat & I d & $2-7 d$ & $8-14 \mathrm{~d}$ & $>14 \mathrm{~d}$ & \\
\hline 1 & Abebe FA et al. $2012^{24}$ & 16.6 & 79.4 & 5.3 & 3.7 & 79.4 & 1.69 & 10.47 & 51.69 & 28.04 & 8.11 & 51.7 \\
\hline 2 & Afriyie DK et al. $2017^{22}$ & 57.6 & 39.4 & 1.5 & 1.5 & 100 & 12 & 43.4 & 48.6 & 0 & 0 & 85.7 \\
\hline 3 & Ayele AA et al. $2018^{16}$ & 1.5 & 76.9 & 1.5 & 20 & 80.1 & 0 & 5.1 & 25.9 & 37.2 & 31.8 & 53 \\
\hline 4 & Ayinalem GA et al. $2013^{25}$ & 9.5 & 63.6 & 0.9 & 25.9 & 77.4 & 8.5 & 13.3 & 76.6 & 2.8 & 1.3 & 52.6 \\
\hline 5 & Bantie et al. $2014^{26}$ & - & - & - & - & 86 & - & - & - & - & - & 82 \\
\hline 6 & Berhe $\mathrm{YH}$ et al. $2019^{15}$ & 5.5 & 94.5 & 0 & 0 & 50.5 & 11.4 & 20 & 28.4 & 35.5 & 4.7 & 26.6 \\
\hline 7 & Eulambius $M$ et al. $2019^{27}$ & 19 & 74 & 0 & 1 & 18 & 0 & 7 & 88 & 5 & 0 & 78 \\
\hline 8 & Manirakiza L et al. $2019^{28}$ & 72.9 & 22.9 & 6 & 3.6 & 31.2 & 15.6 & 50 & 32.2 & 2.2 & 0 & 55 \\
\hline 9 & Sasi P et al. $2019^{29}$ & 87.7 & 11.1 & 0.5 & 0.5 & 0 & 0 & 15.6 & 33.9 & 48.3 & 2.2 & \\
\hline 10 & Hussien LA. $2019^{23}$ & 23.6 & 71.7 & 0.8 & 3.9 & 94.2 & 4.7 & 5.5 & 70.1 & 17.3 & 2.4 & 71.7 \\
\hline 11 & Negese $S$ et al. $2017^{30}$ & 0 & 73.5 & 0 & 26.5 & 87.8 & 0 & 1.2 & 83.9 & 13.6 & 1.2 & 18 \\
\hline 12 & Shimels Tet al. $2015^{31}$ & 0 & 78.6 & 18.6 & 2.8 & 95.8 & 5.1 & 14.5 & 68.1 & 9.3 & 3 & 91.6 \\
\hline
\end{tabular}

Note: NB, some of the included studies did not report information on the appropriateness of daily dose, frequency and duration of ceftriaxone. Abbreviations: Stat, the first single dose; ref, reference.

reported in a recent review of Ethiopian studies. ${ }^{35}$ This difference may be due to the different local antimicrobial resistance pattern, drug availability and study population. This review targeted ceftriaxone use only, while the latter considered all types of antimicrobials. In addition, the extent of appropriate ceftriaxone use is lower than the study done in the USA ambulatory patients, reported a $69.8 \%{ }^{36}$ This may be due to organized healthcare system, adequate drug supply system and availability of blood culture in the USA.

Our review also revealed that a median of $48.5 \%$ of patients used $\leq 2 \mathrm{gm}$ of ceftriaxone daily, while the majority of patients (88.0\%) got $\leq 2 \mathrm{gm}$ of ceftriaxone in Lee h et al. study. ${ }^{37}$ The different diagnoses and severity of infections between the two studies may be responsible for this gap. The median prevalence of patients with appropriate ceftriaxone daily dose was $79.8 \%$ (IQR: 40.9-91.0\%). On the contrary, a lower median of (55\%, IQR: $52.2-80)$ patients got an appropriate duration of ceftriaxone. The availability of a simplified once-daily dose of ceftriaxone has given an opportunity for healthcare workers to prescribe or administer an appropriate daily dose of ceftriaxone. In addition, the empiric use of ceftriaxone as first line for various infections, and then changed to other alternative medications due to poor prognosis, inadequate supply, toxicities or the change of provisional diagnosis may contribute to inappropriate duration of ceftriaxone.

The review has the following strengths: It is the first systematic review focusing on a single antibiotic, and comprehensively involving studies from every corner of the SSA. On the other hand, as studies are heterogeneous in terms of study population and design, it is problematic to perform a pooled prevalence. In addition, some studies did not report specific information on the appropriateness of daily dose, frequency and duration of ceftriaxone, which could alter the analysis.

\section{Conclusion}

The review revealed that ceftriaxone was inappropriately prescribed to more than half of the patients. Of which, approximately half the patients took wrong duration of ceftriaxone. In contrast, due to ease of administration and availability in a single dose, more than three-fourths of the patients got appropriate daily dose. Ceftriaxone is one of the cost-effective broad-spectrum and safe antibiotics used to manage mild to life threatening infections, particularly in low-income countries. Hence, it should be reserved, and used appropriately. Therefore, prescribers should take this into 
consideration, while they are prescribing, and stick to the updated treatment guideline. In addition, initiating or strengthening antimicrobial stewardship program is of paramount importance for the rational use of ceftriaxone. Further, researchers have to investigate reasons and associated information for inappropriate use of ceftriaxone to design customized relevant prevention strategies.

\section{Abbreviations}

IQR, Interquartile Range; PRISMA, Preferred Reporting Items for Systematic Reviews and Meta-Analyses; SAP, Surgical Antibiotic Prophylaxis; SSA, Sub-Saharan Africa; SSI, Surgical Site Infection.

\section{Data Sharing Statement}

The datasets used during the current study are available from the corresponding author on a reasonable request.

\section{Acknowledgments}

We would like to acknowledge the Department of Pharmacology and Clinical Pharmacy, School of Pharmacy, College of Health Science, Addis Ababa University, Addis Ababa, Ethiopia.

\section{Author Contributions}

All authors made a significant contribution to the work reported, in the conception, study design, execution, acquisition of data, analysis, and interpretation; took part in drafting, revising, or critically reviewing the article; gave final approval of the version to be published; have agreed on the journal to which the article has been submitted, and agree to be accountable for all aspects of the work.

\section{Funding}

This research received no specific grant from any funding agency in the public, commercial or not-for-profit sectors.

\section{Disclosure}

The authors declared that they have no conflicts of interest in this work.

\section{References}

1. Chapagain K, Pokharel R, Paranjape BD. Evaluation of prescription pattern and rational prescribing in Eastern Nepal. J Nobel Med Coll. 2016;5(1):32-36. doi:10.3126/jonmc.v5i1.15762

2. Sulis G, Adam P, Nafade V, et al. Antibiotic prescription practices in primary care in low- and middle-income countries: a systematic review and meta-analysis. PLoS Med. 2020;17(6):e1003139. doi:10.1371/journal.pmed.1003139
3. Afari-Asiedu S, Oppong FB, Tostmann A, et al. Determinants of inappropriate antibiotics use in rural central Ghana using a mixed methods approach. Front Public Health. 2020;8:90. doi:10.3389/ fpubh. 2020.00090

4. Zhao H, Wei L, Li H, et al. Appropriateness of antibiotic prescriptions in ambulatory care in China: a nationwide descriptive database study. Lancet Infect Dis. 2021;21(6):847-857. doi:10.1016/S14733099(20)30596-X

5. Summoro TS, Gidebo KD, Kanche ZZ, Woticha EW. Evaluation of trends of drug-prescribing patterns based on WHO prescribing indicators at outpatient departments of four hospitals in southern Ethiopia. Drug Des Devel Ther. 2015;9:4551-4557. doi:10.2147/ DDDT.S83588

6. Tellado JM, Sen SS, Caloto MT, Kumar RN, Nocea G. Consequences of inappropriate initial empiric parenteral antibiotic therapy among patients with community-acquired intra-abdominal infections in Spain. Scand J Infect Dis. 2007;39(11-12):947-955. doi:10.1080/ 00365540701449377

7. Marquet K, Liesenborgs A, Bergs J, Vleugels A, Claes N. Incidence and outcome of inappropriate in-hospital empiric antibiotics for severe infection: a systematic review and meta-analysis. Crit Care. 2015;19(1):63. doi:10.1186/s13054-015-0795-y

8. Tefera GM, Feyisa BB, Kebede TM. Antimicrobial use-related problems and their costs in surgery ward of Jimma University Medical Center: prospective observational study. PLoS One. 2019;14(5): e0216770. doi:10.1371/journal.pone. 0216770

9. Shallcross LJ, Davies DS. Antibiotic overuse: a key driver of antimicrobial resistance. Br J Gen Pract. 2014;64(629):604-605. doi:10.3399/bjgp14X682561

10. Castro-Sánchez E, Moore LS, Husson F, Holmes AH. What are the factors driving antimicrobial resistance? Perspectives from a public event in London, England. BMC Infect Dis. 2016;16(1):465. doi:10.1186/s12879-016-1810-x

11. Llor C, Bjerrum L. Antimicrobial resistance: risk associated with antibiotic overuse and initiatives to reduce the problem. Ther $A d v$ Drug Saf. 2014;5(6):229-241. doi:10.1177/2042098614554919

12. World Health Organisation. Antimicrobial resistance: key facts; 2021. Available from: https://www.who.int/news-room/fact-sheets/detail/ antimicrobial-resistance. Accessed June 6, 2021.

13. Demoz GT, Kasahun GG, Hagazy K, et al. Prescribing pattern of antibiotics using WHO prescribing indicators among inpatients in Ethiopia: a need for antibiotic stewardship program. Infect Drug Resist. 2020;13:2783-2794. doi:10.2147/IDR.S262104

14. Sonda TB, Horumpende PG, Kumburu HH, et al. Ceftriaxone use in a tertiary care hospital in Kilimanjaro, Tanzania: a need for a hospital antibiotic stewardship programme. PLoS One. 2019;14(8):e220261. doi:10.1371/journal.pone.0220261

15. Berhe YH, Amaha ND, Ghebrenegus AS. Evaluation of ceftriaxone use in the medical ward of Halibet National Referral and teaching hospital in 2017 in Asmara, Eritrea: a cross sectional retrospective study. BMC Infect Dis. 2019;19(1):465. doi:10.1186/s12879-0194087-z

16. Ayele AA, Gebresillassie BM, Erku DA, et al. Prospective evaluation of Ceftriaxone use in medical and emergency wards of Gondar university referral hospital, Ethiopia. Pharmacol Res Perspect. 2018;6(1):e00383. doi:10.1002/prp2.383

17. Gashe F, Mulisa E, Mekonnen M, Zeleke G. Antimicrobial resistance profile of different clinical isolates against third-generation cephalosporins. J Pharm (Cairo). 2018;2018:5070742.

18. Ampaire L, Muhindo A, Orikiriza P, Mwanga-Amumpaire J, Bebell L, Boum Y. A review of antimicrobial resistance in East Africa. Afr J Lab Med. 2016;5(1):432. doi:10.4102/ajlm.v5i1.432

19. Lieberman JM. Appropriate antibiotic use and why it is important: the challenges of bacterial resistance. Pediatr Infect Dis J. 2003;22 (12):1143-1151. doi:10.1097/01.inf.0000101851.57263.63 
20. Moher D, Shamseer L, Clarke M, et al. Preferred reporting items for systematic review and meta-analysis protocols (PRISMA-P) 2015 statement. Syst Rev. 2015;4(1):1. doi:10.1186/2046-4053-4-1

21. Wells GA, Shea B, O'Connell D, et al.The Newcastle-Ottawa Scale (NOS) for assessing cross-sectional studies. The Ottawa Hospital Research Institute; 2021. Available from: http://www.ohri.ca/pro grams/clinical_epidemiology/oxford.asp. Accessed July 15, 2021.

22. Afriyie DK, Amponsah SK, Dogbey J, et al. A pilot study evaluating the prescribing of ceftriaxone in hospitals in Ghana: findings and implications. Hosp Pract (1995). 2017;45(4):143-149. doi:10.1080/ 21548331.2017.1348139

23. Hussien LA, Awad M. Prescribing pattern of ceftriaxone among inpatients admitted to emergency room in military hospital-Omdurman, Sudan. J Qual Healthcare Eco. 2019;2(6):1-6.

24. Abebe FA, Berhe DF, Berhe AH, Hishe HZ, Akaleweld MA. Drug use evaluation of ceftriaxone: the case of Ayder Referral Hospital, Mekelle, Ethiopia. Int J Pharm Sci Res. 2012;3(7):2191.

25. Ayinalem GA, Gelaw BK, Belay AZ, Linjesa JL. Drug use evaluation of ceftriaxone in medical ward of Dessie Referral Hospital, North East Ethiopia. Int J Basic Clin Pharmacol. 2013;2(6):711-717. doi:10.5455/2319-2003.ijbcp20131208

26. Bantie L. Drug use evaluation (DUE) of Ceftriaxone injection in the in-patient wards of Felege Hiwot Referral Hospital (FHRH), Bahir Dar, North Ethiopia. Int J Pharm Sci. 2014;4:671-676.

27. Eulambius M, Osward N. Evaluation of Ceftriaxone utilization among selected hospitals in Dar-es-Salaam, Tanzania. JDDT. 2019;9(6):7-11.

28. Manirakiza L, Nambasa V, Nanyonga S, et al. Drug use evaluation (DUE) of ceftriaxone in mubende regional referral hospital, Uganda: a cross-sectional survey. J Pharm Pharmacol. 2019;03:105-115.

29. Sasi PG. Ceftriaxone prescription atMuhimbili National Hospital. Tanzan J Health Res. 2020;21(2):1-13. doi:10.4314/thrb.v21i2.7
30. Negese S, Ma AM, Asmamaw D, Omer M, Tenaw A. Evaluation of ceftriaxone use for hospitalized patients in Ethiopia: the case of a referral hospital. IJPSR. 2017;3:2.

31. Shimels T, Bilal AI, Mulugeta A. Evaluation of Ceftriaxone utilization in internal medicine wards of general hospitals in Addis Ababa, Ethiopia: a comparative retrospective study. J Pharm Policy Pract. 2015;8:26. doi:10.1186/s40545-015-0047-1

32. Geresu G, Yadesa T, Deresa B. Drug use evaluation of ceftriaxone in medical ward of mizan aman general hospital, Bench Maji Zone, South Western Ethiopia. J Bioanal Biomed. 2018;10:127-131. doi:10.4172/1948-593X.1000221

33. Muhammed OS, Nasir BB. Drug use evaluation of ceftriaxone in ras-desta memorial general hospital, Ethiopia. Drug Healthc Patient Saf. 2020;12:161-168. doi:10.2147/DHPS.S260364

34. Richards DM, Heel RC, Brogden RN, Speight TM, Avery GS. Ceftriaxone. A review of its antibacterial activity, pharmacological properties and therapeutic use. Drugs. 1984;27(6):469-527. doi:10.2165/00003495-198427060-00001

35. Muhie OA. Antibiotic use and resistance pattern in Ethiopia: systematic review and meta-analysis. Int $J$ Microbiol. 2019;2019:2489063. doi:10.1155/2019/2489063

36. Fleming-Dutra KE, Hersh AL, Shapiro DJ, et al. Prevalence of inappropriate antibiotic prescriptions among us ambulatory care visits, 2010-2011. JAMA. 2016;315(17):1864-1873. doi:10.1001/ jama.2016.4151

37. Lee H, Jung D, Yeom JS, et al. Evaluation of ceftriaxone utilization at multicenter study. Korean J Intern Med. 2009;24(4):374-380. doi:10.3904/kjim.2009.24.4.374
Infection and Drug Resistance

\section{Publish your work in this journal}

Infection and Drug Resistance is an international, peer-reviewed openaccess journal that focuses on the optimal treatment of infection (bacterial, fungal and viral) and the development and institution of preventive strategies to minimize the development and spread of resistance. The journal is specifically concerned with the epidemiology of

\section{Dovepress}

antibiotic resistance and the mechanisms of resistance development and diffusion in both hospitals and the community. The manuscript management system is completely online and includes a very quick and fair peerreview system, which is all easy to use. Visit http://www.dovepress.com/ testimonials.php to read real quotes from published authors. 